\title{
Macrocyclic and polymeric lanthanide chelates: from physico-chemical studies to biomedical applications
}

\author{
M.G. Duarte ${ }^{\mathrm{a}, \mathrm{b}}$, M.I.M. Prata ${ }^{\mathrm{a}}$, M.H.M. Gil ${ }^{\mathrm{b}}$, C.F.G.C. Geraldes ${ }^{\mathrm{a}, *}$ \\ ${ }^{\mathrm{a}}$ Department of Biochemistry and Centre of Neuroscience, Faculty of Science and Technology, University of Coimbra, 3000 Coimbra, Portugal \\ ${ }^{\mathrm{b}}$ Department of Chemical Engineering, Faculty of Science and Technology, University of Coimbra, Coimbra, Portugal
}

\begin{abstract}
The improvement of commonly used $\mathrm{Gd}^{3+}$-based MRI contrast agents requires the design of new chelates with optimised in vivo efficacy, pharmacokinetic properties and specificity. The molecular parameters determining the nuclear relaxivity of the cationic chelate $[\mathrm{Gd}(\mathrm{DO} 2 \mathrm{~A})]^{+}$, as well as of some copolymers of $[\mathrm{Gd}(\mathrm{DTPA})]^{2-}$ with diamines, were obtained using spectroscopic techniques. In both cases, the resulting too slow inner-sphere water exchange rate limits the relaxivity increase expected, respectively, from an increased water coordination number, and some degree of rotational restriction, although in the latter case, the relaxivity shows a maximum in the $30 \mathrm{MHz}$ proton frequency region. The use of the polymeric compounds as MR angiography agents is limited by their fast uptake from the blood pool of Wistar rats. The use of scintigraphic diagnostic agents critically depends on their targeting properties. ${ }^{111} \mathrm{In}^{3+}$ and ${ }^{153} \mathrm{Sm}^{3+}$ chelates of DTPA derivatives, containing albumin binding or hepato-specific synthons, show different organ specificity, albumin binding properties and excretion pathways and kinetics, as shown by biodistribution and gamma imaging studies of Wistar rats. The ${ }^{111} \mathrm{In}^{3+}$, ${ }^{153} \mathrm{Sm}^{3+}, \mathrm{Gd}^{3+}$ and $\mathrm{Tm}^{3+}$ chelates of the tetraaza-phosphonate macrocycle DOTP ${ }^{8-}$ also show high bone uptake specificity.

(C) 2002 Elsevier Science B.V. All rights reserved.
\end{abstract}

Keywords: Macrocyclic lanthanide complexes; Polymeric lanthanide compounds; MRI contrast agents; Gamma scintigraphy

\section{Introduction}

Chelates of $\mathrm{Gd}^{3+}$ have found widespread application as contrast agents (CAs) for magnetic resonance imaging (MRI) [1-5]. The paramagnetic $\mathrm{Gd}^{3+}$ ion in these compounds has an enhancing effect on the relaxation rate of the water protons in its proximity, which may lead to an increase of the contrast in the images and a decrease of the imaging time. Encapsulation of $\mathrm{Gd}^{3+}$ in a strongly chelating ligand is necessary, since the $\mathrm{Gd}^{3+}$ aquo ion is highly toxic, whereas the chelates are not. Thus an important requirement that a $\mathrm{Gd}^{3+}$ complex must meet for in vivo applicability is high stability, both thermodynamic and kinetic. The chelating ligand preferably should leave enough space on the $\mathrm{Gd}^{3+}$ ion for coordination of water. The coordinated water exchanges with the bulk and as a result an overall contrast enhancement (reduction of the water proton relaxation rate) may be obtained. Currently, commercially available CAs are derivatives of: (i) DTPA (DTPA, diethylenetriamine- $N, N, N^{\prime}, N^{\prime \prime}, N^{\prime \prime}$-pentaacetate) and (ii) the macrocyclic ligand DOTA (DOTA, 1,4,7,10-

*Corresponding author.

E-mail address: geraldes@cygnus.ci.uc.pt (C.F.G.C. Geraldes). tetraazacyclododecane-1,4,7,10-tetraacetate) (see Scheme 1).

The overwhelming success of the CAs and the rapid development of the MRI technique have given rise to a continuing demand for new generations of CAs that are more effective and selective. The molecular parameters determining their nuclear relaxivity must be optimised, in order to maximize their efficiency. Following predictions of relaxation theory [1-5], we investigated in this work the effect of an increase of the inner-sphere water coordination number $(q)$ from 1 to 2 or 3 , by studying the

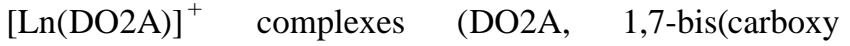
methyl)-1,4,7,10-tetraazacyclododecane, Scheme 1), resulting from the elimination of two carboxylates from the ligand DOTA. Higher relaxation rates are also obtained upon increase of the rotational correlation time of the $\mathrm{Gd}^{3+}$ complexes, which may be achieved by non-covalent or covalent binding of low-molecular weight $\mathrm{Gd}^{3+}$ chelates to macromolecules or polymers [3-5]. These conjugates might have prolonged residence time in the cardiovascular system, with potential applications in MRI angiography (MRA) [3-5]. We report the biophysical characterization and in vivo pharmacokinetics in Wistar rats of two linear polyamide conjugates of $\mathrm{Gd}(\mathrm{III})$-DTPA (Gd(DTPA- 


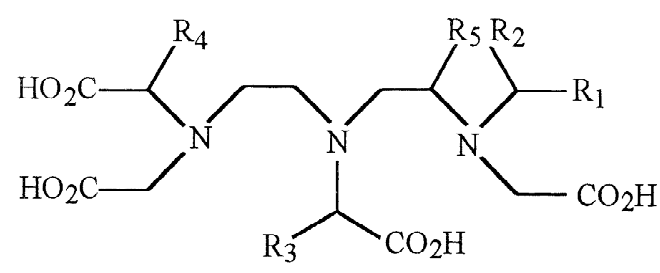

$\mathrm{R}_{1}=\mathrm{CO}_{2} \mathrm{H} ; \mathrm{R}_{2}=\mathrm{R}_{3}=\mathrm{R}_{4}=\mathrm{R}_{5}=\mathrm{H}$

DTPA

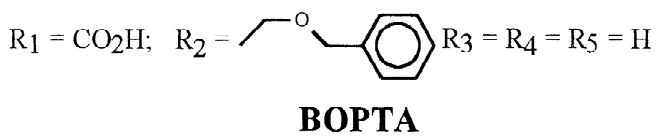

$\mathrm{R}_{1}-\mathrm{CO}_{2} \mathrm{H} ; \quad \mathrm{R}_{2}=\mathrm{R}_{3}=\mathrm{R}_{4}=\mathrm{H} \quad \mathrm{R}_{5}=\square \longrightarrow$ OEt

EOB-DTPA

$\mathrm{R}_{1}-\mathrm{CO}_{2} \mathrm{H} ; \mathrm{R}_{2}=\mathrm{R}_{3}=\mathrm{R}_{4}=\frown \mathrm{O} \bigcirc \mathrm{R}_{5}=\mathrm{H}$

DTPA $(\text { BOM })_{3}$

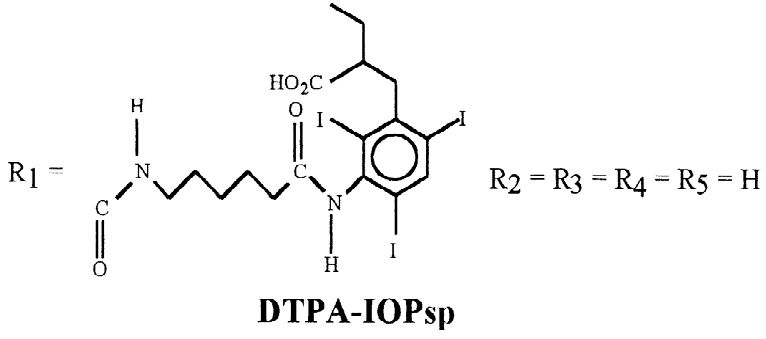

Scheme 1

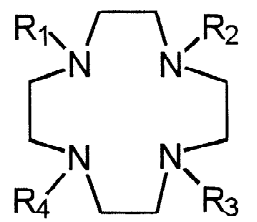

$$
\begin{array}{ll}
\mathrm{R}_{1}=\mathrm{R}_{2}=\mathrm{R}_{3}=\mathrm{R}_{4}=\mathrm{CH}_{2} \mathrm{PO}_{3} \mathrm{H}_{2}: & \text { DOTP } \\
\mathrm{R}_{1}=\mathrm{R}_{2}=\mathrm{R}_{3}=\mathrm{R}_{4}=\mathrm{CH}_{2} \mathrm{COOH}: & \text { DOTA } \\
\mathrm{R}_{1}=\mathrm{R}_{3}=\mathrm{CH}_{2} \mathrm{COOH} ; \mathrm{R}_{2}=\mathrm{R}_{4}=\mathrm{H}: \text { DO2A }
\end{array}
$$
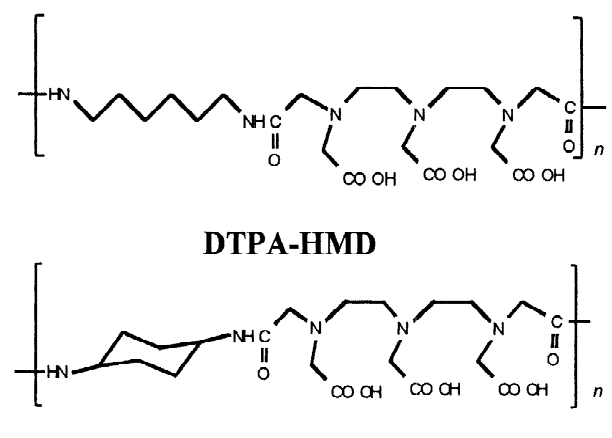

DTPA-CHD
HMD) and Gd(DTPA-CHD), Scheme 1), obtained by copolymerization of DTPA with two diamines. Furthermore, contrast improvements may be achieved by attaching substituents on the ligand such that higher organ or tissue specificity is obtained [4,5]. New generations of CAs are also being developed that are reporters of their biochemical environment, allowing, for example, visualization of $\mathrm{pH}$ differences, oxygen concentrations, gene expression and therapeutic drug delivery [4,5].

The utility of scintigraphic diagnostic agents critically depends on their targeting properties, which are achieved by adequate ligand design [6]. Two DTPA derivatives, a mono-amide derivative containing an iodinated synthon, DTPA-IOPsp $\quad(3\{[6[[[2-[(2$ aminoethyl $)$ amino $]$ ethyl $]-$ amino]acetylamino] - 1 - oxo - ethylamino] - $\alpha$ - ethyl - 2,4,6triiode $\}$ benzene propanoic acid) and DTPA(BOM) (\{2 - (benzyloxymethyl) - 6,9 - bis(1 - carboxy - 2-benzyloxyethyl)-3,9-bis-(carboxymethyl)-3,6,9-triaza\}undecanoic acid) (Scheme 1), radiolabelled with ${ }^{111} \mathrm{In}^{3+}$ and ${ }^{153} \mathrm{Sm}^{3+}$, and the ${ }^{111} \mathrm{In}^{3+}$ and ${ }^{153} \mathrm{Sm}^{3+}$ chelates of the tetraaza-phosphonate macrocycle DOTP $^{8-}(1,4,7,10$ tetraazacyclododecane - $1,4,7,10 \quad$ - tetramethylenephosphonate, Scheme 1) were studied as potential hepatospecific gamma scintigraphic agents and bone-spe- cific agents, respectively, using gamma imaging and biodistribution techniques in Wistar rats.

\section{Optimizing $\mathrm{Gd}^{3+}$-based MRI contrast agents}

Relaxation theory shows that the currently commercially available CAs are far from optimal with regard to relaxation enhancement. An improvement may be achieved via rational design of the ligands, which requires insight into the parameters that govern the relaxivity, $r_{1}$ (enhancement of the water proton relaxation rate, expressed in $\mathrm{s}^{-1} \mathrm{mM}^{-1}$ $\mathrm{Gd}^{3+}$ ). Extensive studies in this field [1-5] have shown that each of these parameters is related to the solution structures and dynamics of the concerning complexes. Higher relaxivities may be achieved by, for example, (i) the design of the environment of the water coordination site, so that the water exchange rate will not limit the overall relaxivity $\left(\tau_{\mathrm{m}}<T_{1 \mathrm{~m}}\right.$, with $\tau_{\mathrm{m}}$ being the residence time of a water molecule in the first coordination sphere, and $T_{1 \mathrm{~m}}$ the water proton longitudinal relaxation time), (ii) an increase of the molecular weight of the compounds, in order to increase the rotational correlation time, $\tau_{\mathrm{R}}$, (iii) an increase of the rigidity of the complex, which gives rise to 
an increase of the electronic relaxation time of the $\mathrm{Gd}^{3+}$ ion, $\tau_{\mathrm{s} 0}$, or (iv) an increase of the inner-sphere water coordination number $(q)$ from 1 to 2 or 3 .

An important drawback of $\left[\mathrm{Gd}(\mathrm{DOTA})\left(\mathrm{H}_{2} \mathrm{O}\right)\right]^{-}$ (DOTAREM $^{\mathrm{TM}}$, Guerbet, France), which is common to all extracellular contrast agents, is the lack of any tissuespecificity. Attempts to obtain tissue-specific MRI contrast agents have led to the synthesis of positively charged Gd(III) complexes which proved promising in bone targeting by their ability to mimic the interaction of biological cations (e.g. $\mathrm{Ca}^{2+}$ ) with the anionic bone surface [7]. The elimination of two carboxylates from the ligand DOTA results in a decreased stability of the corresponding $[\mathrm{Ln}(\mathrm{DO} 2 \mathrm{~A})]^{+}$complexes, but the increased number of inner-sphere water molecules may significantly increase the relaxivity of the $[\mathrm{Gd}(\mathrm{DO} 2 \mathrm{~A})]^{+}$complex. The solution structure and dynamics of the $\left[\mathrm{Ln}(\mathrm{DO} 2 \mathrm{~A})\left(\mathrm{H}_{2} \mathrm{O}\right)_{q}\right]^{+}$complexes have been studied by ${ }^{1} \mathrm{H}$ and ${ }^{17} \mathrm{O} \mathrm{NMR}$, relaxometry, UV-vis and luminescence [8,9]. The smaller extent of encapsulation of the $\mathrm{Ln}^{3+}$ ions by the DO2A ligand leads to a less rigid macrocyclic [3333] structure than in the DOTA chelates, as indicated by the ${ }^{1} \mathrm{H}$ NMR resonances of its $\mathrm{CH}_{2}$ protons [8]. Luminescence studies have shown that one of the inner-sphere water molecules of the $\mathrm{Eu}^{3+}$ chelate hydrolyses at slightly basic $\mathrm{pH}$ with a $\mathrm{p} K_{\mathrm{h}}$ of $8.1 \pm 0.3$ [9].

We studied the hydration state of the whole series of $[\mathrm{Ln}(\mathrm{DO} 2 \mathrm{~A})]^{+}$complexes in aqueous solution at $\mathrm{pH} 7.0$ by measuring their water lanthanide induced ${ }^{17} \mathrm{O}$ shifts (LIS). Their contact contribution indicates a decrease of the inner-sphere water coordination number of the $\left[\mathrm{Ln}(\mathrm{DO} 2 \mathrm{~A})\left(\mathrm{H}_{2} \mathrm{O}\right)_{q}\right]^{+}$complexes from $q=3$ for $\mathrm{Ln}=$ $\mathrm{Ce} \rightarrow \mathrm{Eu}$, to $q=2$, for $\mathrm{Ln}=\mathrm{Tb} \rightarrow \mathrm{Yb}$ [10]. A temperaturedependent UV-vis study of the 578-582 nm ${ }^{7} \mathrm{~F}_{0} \rightarrow{ }^{5} \mathrm{D}_{0}$ transition band of $\left[\mathrm{Eu}(\mathrm{DO} 2 \mathrm{~A})\left(\mathrm{H}_{2} \mathrm{O}\right)_{q}\right]^{+}$in aqueous solution, shows that this complex is present in an equilibrium between eight- and nine-coordinate species with $q=2$ and $q=3$ :

$$
\left[\mathrm{Eu}(\mathrm{DO} 2 \mathrm{~A})\left(\mathrm{H}_{2} \mathrm{O}\right)_{2}\right]^{+}+\mathrm{H}_{2} \mathrm{O} \Leftrightarrow\left[\mathrm{Eu}(\mathrm{DO} 2 \mathrm{~A})\left(\mathrm{H}_{2} \mathrm{O}\right)_{3}\right]^{+}
$$

The hydration equilibrium parameters obtained, $K_{\mathrm{Eu}}^{298}=$ $(4.0 \pm 0.2), \Delta H^{\circ}=-(12.1 \pm 1) \mathrm{kJ} \mathrm{mol}^{-1}$ and $\Delta S^{\circ}=-$ (28.9 \pm 3$) \mathrm{J} \mathrm{mol}^{-1} \mathrm{~K}^{-1}$, correspond to an average coordination number of 2.65-2.85 in the temperature range 273-363 K [10]. We also used a variable temperature, multiple field ${ }^{17} \mathrm{O}$ NMR study combined with direct EPR measurements of the transverse electronic relaxation rates to obtain the parameters determining the proton relaxivity of $\left[\mathrm{Gd}(\mathrm{DO} 2 \mathrm{~A})\left(\mathrm{H}_{2} \mathrm{O}\right)_{2,3}\right]^{+}$. The limited increase in its water exchange rate, $k_{\mathrm{ex}}^{298}=(10 \pm 5) \times 10^{6} \mathrm{~s}^{-1}$, as compared to $\left[\mathrm{Gd}(\mathrm{DOTA})\left(\mathrm{H}_{2} \mathrm{O}\right)\right]^{-}\left(4.8 \times 10^{6} \mathrm{~s}^{-1}\right)$, is the consequence of two opposite effects: a decrease from the positive charge and an increase from the existence of the hydration equilibrium. The value of $\tau_{\mathrm{R}}^{298}=40 \pm 1 \mathrm{ps}$ is short, and the electronic relaxation rate $\left(1 / T_{2 \mathrm{e}} \sim 1.2 \times 10^{10} \mathrm{~s}^{-1}\right)$ is relatively fast relative to $\left[\mathrm{Gd}(\mathrm{DOTA})\left(\mathrm{H}_{2} \mathrm{O}\right)\right]^{-}\left(1.3-2.4 \times 10^{9}\right.$ $\mathrm{s}^{-1}$ for $\left.B_{\mathrm{o}}=0.34 \mathrm{~T}\right)$. The values of all these parameters have an adverse effect on the expected increase of the proton relaxivity of the $\left[\mathrm{Gd}(\mathrm{DO} 2 \mathrm{~A})\left(\mathrm{H}_{2} \mathrm{O}\right)_{2,3}\right]^{+}$complex containing a hydration equilibrium among several inner sphere water molecules.

Another way of obtaining higher relaxivities is by increasing the rotational correlation time, $\tau_{\mathrm{R}}$, of the $\mathrm{Gd}^{3+}$ complexes, through their covalent or non-covalent binding to macromolecules or polymers. Thus, several blood pool CAs for MRA examinations have been developed, through conjugation of low molecular weight $\mathrm{Gd}^{3+}$-chelate complexes, such as $\operatorname{Gd}(\mathrm{DTPA})^{2-}$ or Gd(DOTA) ${ }^{-}$, to natural or synthetic polymeric materials, like polysaccharides, human serum albumin (HSA), polyaminoacids like polylysine and polyornithine or dendrimers [5]. Some linear polymers of DTPA have also been prepared in which the chelate is incorporated directly in the polymeric chain [11]. We synthesised two of such linear polyamide conjugates of Gd(DTPA $)^{2-}$, where the polymeric ligands were obtained by copolymerization of DTPA with two different diamines, the linear and conformationally flexible 1,6-hexanediamine (HMD) and the cyclic and conformationally more rigid trans-1,4-cyclohexadiamine (CHD) [12]. The polymers DTPA-HMD and DTPA-CHD (Scheme 1) were characterised by high resolution nuclear magnetic resonance (NMR) spectroscopy and size exclusion chromatography (SEC), showing low polydispersity. Their molecular flexibility in solution was studied using ${ }^{13} \mathrm{C}$ spin-lattice relaxation time measurements, indicating that the cyclohexanediamine linking moiety of the DTPA-HMD polymer is more rigid than that of DTPA-CHD. The influence of the flexibility of the linking functionalities on the relaxivity of the $\mathrm{Gd}^{3+}$-DTPA-polymer conjugates was studied by water nuclear magnetic relaxation dispersion (NMRD). The relaxivity of the [Gd(DTPA-CHD)] polymer was only slightly higher than that of the [Gd(DTPAHMD)] polymer, and only two times higher than the usual values for small Gd-DTPA-like chelates. The low relaxivities obtained for both polymers, much lower than expected from the polymer apparent molecular weights, result from their substantial residual flexibility due to the rapid internal rotational motion of the linking moieties between the $\mathrm{Gd}^{3+}$-chelate in the polymeric chain, and also from a too long, non-optimal, value of the inner-sphere water exchange rate [12]. The in vivo pharmacokinetics of these polymeric compounds in Wistar rats was studied by the decay of blood relaxivity with the time after injection of the polymers, showing very short blood half-lifes, $t_{1 / 2} \sim$ $20 \mathrm{~min}$. Their very fast clearance from blood indicates that these flexible, hydrophilic, polymeric compounds are of limited value as blood pool CAs for MRA.

\section{Targeting CAs and scintigraphic agents}

New CAs, more efficient than the unspecific intracellular ones, are being developed that may be directed to 
targets of interest, thereby achieving higher local concentrations at lower dosages. Examples are CAs that are specific for organs, diseased tissue or that are able to recognize particular biochemicals. Usually, this is achieved by functionalization of the ligands in [Gd(DTPA) $]^{2-}$ and [Gd(DOTA) $]^{-}$type complexes. For example, complexes of DTPA with lipophilic side chains ([Gd(BOPTA) $]^{2-}$ (Multihance $^{\text {тм }}$, Bracco) and [Gd(EOB-DTPA) $]^{2-}$ (Eovist $^{\mathrm{TM}}$, Schering), Scheme 1) have been introduced as hepatobiliary CAs [5], as they undergo $>35 \%$ biliary excretion and enter the hepatocytes via a combination of passive diffusion and a carrier-mediated mechanism [5]. High molecular weight compounds and liposomes have also shown potential as CAs for lymphography [5].

Studies on potential tumor-specific CAs based on conjugates of antibodies attached to conjugates of polymeric carriers and low molecular $\mathrm{Gd}^{3+}$ chelates have been reported [5]. An alternative approach takes advantage of the negative charge of certain tumors, whereby positively charged poly(amino acids) such as polyornithine or polyarginine are selectively bound, which on their turn may serve as targets for a negatively charged $\mathrm{Gd}^{3+}$ chelate, such as a DO3A derivative containing an additional pendant arm with phosphonate and carboxylate groups [5]. Another strategy for selective delivery of CAs at cancer cells exploits the intrinsic overexpression of sialic acid in them. Upon incubation of cancer cells with peracetylated $N$-levulinoylmannosamine, the sialoside biosynthetic pathway affords $N$-levulinoyl sialic acid, the ketone group of which can be a target for a $\mathrm{Gd}^{3+}$ complex of an aminooxyfunctionalized DTPA derivative [5]. Lanthanide complexes of texaphyrin $[\operatorname{Ln}(\operatorname{Tex})]^{2+}$ have been shown to accumulate in tumors and atherosclerotic plaque and these compounds are being tested in photosensitized and radiation sensitized treatment of cancer and cardiovascular diseases [5]. Texaphyrin is an expanded porphyrin ligand with five $\mathrm{N}$ donor atoms.

The use of scintigraphic diagnostic agents in nuclear medicine, such as chelates of the $\gamma$-emitters ${ }^{111} \mathrm{In}^{3+}$ and ${ }^{153} \mathrm{Sm}^{3+}$, also critically depends on their targeting properties, which is achieved by adequate ligand design. We studied two DTPA derivatives containing recognition synthons. The iodinated synthon containing the iopanoic acid moiety, present in the DTPA-IOPsp ligand, gives its $\mathrm{Gd}^{3+}$ complex a $65 \%$ hepatobiliary elimination, while the three benzyloxymethyl (BOM) groups in the $\mathrm{DTPA}(\mathrm{BOM})_{3}$ ligand gives its $\mathrm{Gd}^{3+}$ complex a high binding affinity to HSA [13,14]. These ligands, radiolabelled with ${ }^{111} \mathrm{In}^{3+}$ and ${ }^{153} \mathrm{Sm}^{3+}$, were studied as potential hepatospecific gamma scintigraphic agents by biodistribution, biokinetics and clearance studies in Wistar rats using gamma imaging techniques [15]. The in vivo studies show that their main excretory pathway is the hepatobiliary system, the complexes of DTPA(BOM) showing even greater hepatobiliary specificity than those of DTPA-IOPsp, perhaps as a consequence of longer blood circulation times due to their strong affinity towards HSA.
The ${ }^{153} \mathrm{Sm}^{3+}$ chelates are also more hepatospecific than the corresponding ${ }^{111} \mathrm{In}^{3+}$ chelates, due to different structures in solution, as studied by NMR [15].

Since highly charged phosphonates are known to localize on bone surfaces [16], $\left[{ }^{153} \mathrm{Sm} \text { (EDTMP) }\right]^{5-}$ (EDTMP, ethylenediamino-tetramethylenephosphonate) is used as a palliative agent for painful bone metastasis [17]. The $\mathrm{Ln}^{3+}$ complexes of the tetraaza-phosphonate macrocycle DOTP $^{8-},[\operatorname{Ln}(\mathrm{DOTP})]^{5-}$, are very stable and well characterized in solution and $[\mathrm{Tm}(\mathrm{DOTP})]^{5-}$ is a very good shift reagent for ${ }^{23} \mathrm{Na}^{+}$NMR of isolated cells, perfused tissues and intact animals [5]. Although [Tm(DOTP) ${ }^{5-}$, after injection in Wistar rats, is cleared from plasma more rapidly than typical lower charged $\mathrm{Gd}^{3+}$-based contrast agents, about $18 \%$ is retained for at least $3 \mathrm{~h}$ in one very slow equilibrating space, from which it is cleared very slowly compared to renal clearance [18]. The assumption that this $18 \%[\mathrm{Tm}(\mathrm{DOTP})]^{5-}$ remains bound to bone after the 3-h washout period was confirmed by gamma scintigraphic biodistribution studies of $\left[{ }^{159} \mathrm{Gd}(\mathrm{DOTP})\right]^{5-}$ in rats, which found that $55 \%$ of the total injected radioactive dose was localized on bone surfaces after $30 \mathrm{~min}$ [19]. Similar results were obtained by us in biodistribution studies of $\left[{ }^{153} \mathrm{Sm}(\mathrm{DOTP})\right]^{5-}$ and $\left[{ }^{111} \operatorname{In}(\mathrm{DOTP})\right]^{5-}$ in Wistar rats. For example, in the second case about $25 \%$ of the total injected radioactive dose was found localized on bone surfaces after $48 \mathrm{~h}$ [20].

\section{Acknowledgements}

We thank BIOMED II (MACE Project) of the E.U. and the Portuguese Foundation of Science and Technology (project Praxis 2/2.2/SAU/1194/95 and grant BD/ 5056795 to M.G. Duarte) for their financial support, Bracco S.p.A., Milan, Italy, for providing the DTPA derivative ligands, Macrocyclics, Richardson, Texas, USA, for the DOTP chelate, and Dr. P.L. Anelli (Bracco S.p.A., Milan, Italy), Dr. J.A. Peters (Delft Technical University, Netherlands), Prof. A.D. Sherry (University of Texas at Dallas, USA), Prof. A.E. Merbach and his group (University of Lausanne, Switzerland), Prof. Robert N. Muller and his group (University of Mons-Hainault, Belgium) and Prof. J.J. Pedroso de Lima (University of Coimbra, Portugal) for discussions and scientific collaborations, including some NMR, NMRD, UV-vis measurements and gamma imaging facilities. This work was carried out within the COST Chemistry D8 and D18 projects of the E.U.

\section{References}

[1] R.B. Lauffer, Chem. Rev. 87 (1987) 901.

[2] J.A. Peters, J. Huskens, D.J. Raber, Prog. Magn. Reson. Spectrosc. 28 (1996) 283.

[3] S. Aime, M. Botta, M. Fasano, E. Terreno, Chem. Soc. Rev. 27 (1998) 19. 
[4] P. Caravan, J.J. Ellison, T.J. McMurry, R.B. Lauffer, Chem. Rev. 99 (1999) 2293

[5] A.E. Merbach, É. Tóth (Eds.), The Chemistry of Contrast Agents in Medical Magnetic Resonance Imaging, Wiley, Chichester, 2001, pp. 193-241.

[6] S. Jurisson, D. Berning, W. Jia, D. Ma, Chem. Rev. 93 (1993) 1137.

[7] W.D. Kim, D.C. Hrncir, G.E. Kiefer, A.D. Sherry, Inorg. Chem. 34 (1995) 2225.

[8] J. Huskens, D. Torres, Z. Kovacs, J.P. André, C.F.G.C. Geraldes, A.D. Sherry, Inorg. Chem. 36 (1997) 1495.

[9] C.A. Chang, Y.-H. Chen, F.-K. Shieh, J. Chem. Soc. Dalton Trans. (1998) 3243

[10] F. Yerly, F. Dunand, E. Tóth, A. Figueirinha, Z. Kovacs, A.D. Sherry, C.F.G.C. Geraldes, A.E. Merbach, Eur. J. Inorg. Chem. (2000) 1001.

[11] K.E. Kellar, P.M. Henrichs, R. Hollister, S.H. Koenig, J. Eck, D. Wei, Magn. Reson. Med. 38 (1997) 712
[12] M.G. Duarte, M.H. Gil, J. Peters, J.M. Colet, L.V. Elst, R.N. Muller, C.F.G.C. Geraldes, Bioconjug. Chem. 12 (2001) 170

[13] P.L. Anelli, L. Calabi, C. de Haën, F. Fedeli, P. Losi, M. Murru, F. Uggeri, Gazz. Chim. Ital. 126 (1996) 89.

[14] S. Aime, M. Chiaussa, G. Digilio, E. Gianolio, E. Terreno, J. Biol. Inorg. Chem. 4 (1999) 766.

[15] M.I.M. Prata, A.C. Santos, M. Neves, C.F.G.C. Geraldes, J.J.P. Lima, submitted.

[16] J. Simon, J.R. Garlich, D.A. Wilson, K. McMillan, Bone Marrow Suppressing Agents, US Patents 4,882,142 and 4,976,950.

[17] W.F. Goeckeler, B. Edwards, W.A. Wolkert, J. Simon, D. Wilson, J. Nucl. Med. 28 (1987) 495.

[18] J.D. Makos, C.R. Malloy, A.D. Sherry, J. Appl. Physiol. 85 (1998) 1800.

[19] G. Kiefer, Dow Chemical Co., unpublished results.

[20] F.C. Alves, M.I.M. Prata, A.C. Santos, M. Neves, J.J.P. Lima, A.D. Sherry, C.F.G.C. Geraldes, submitted. 